\title{
Comparison of visual, impedance spectroscopy and laser fluorescence methods in detecting early carious lesions on occlusal surfaces
}

\author{
Renata Chalas*, Ilona Wojcik-Checinska, Joanna Zubrzycka-Wrobel, \\ Dominika Piatek, Teresa Bachanek
}

Chair and Department of Conservative Dentistry with Endodontics, Medical University of Lublin, Karmelicka 7, 20-081 Lublin, Poland

\begin{tabular}{l}
\hline ARTICLE INFO \\
\hline Received 01 July 2014 \\
Accepted 15 July 2014 \\
\hline
\end{tabular}

Keywords: caries detection, ICDAS,

laser fluorescence, impedance spectroscopy.

\begin{abstract}
The diagnostic management is a very important and integral part of the entire treatment process and has a direct influence on the decision-taking on the choice of the most appropriate form of therapy consistent with current knowledge. Knowledge of the morphology of hard dental tissues lesions has led to the development of quantitative methods for diagnosis and monitoring of dental caries, which enabled the implementation of appropriate treatments aimed at repairing than replacing damaged tissue. The aim of the study was to compare selected diagnostic methods: visual (ICDAS), impedance spectroscopy (CarieScan PRO) and laser fluorescence (Diagnodent Pen) in detecting caries in grooves on the chewing surfaces of molars and premolars. The obtained results indicated a high concordance of measurements performed with the Diagnodent Pen with the results of visual examination and a lower compliance of visual examination with the results obtained using the CarieScan PRO. A combination of visual and tactile method with tests using advanced technology provides greater opportunity to confirm the diagnosis of carious lesions requiring medical intervention.
\end{abstract}

\section{INTRODUCTION}

The diagnosis of caries in times when complex etiopathogenesis of the disease was not known, relied on the presence of macroscopic symptoms, according to Fauchard (eighteenth century) as "broken or eaten tooth." Today, dentistry relies on knowledge of the etiology, pathology, treatment, prognosis and prevention of dental caries, and thus modern diagnosis of the disease is based on the combined results of pathological and etiological tests [11].

The diagnostic management is a very important and integral part of the entire treatment process and has a direct influence on the decision-taking on the choice of the most appropriate form of therapy consistent with current knowledge. Diagnosis entails specific decisions whether to make observations or perform invasive surgery, etc. From the point of view of clinical practice, it is essential to identify the moment in which further observation and

Corresponding author

e-mail: renata.chalas@umlub.pl preventive treatment are not able to stop the progression of the disease, i.e., it is important to maintain a balance between surgical and non-surgical treatment of carious lesions. According to current knowledge, the diagnosis of dental caries in the initial phase of development is the most desirable moment, because only then it is possible to inhibit the progression of the disease without the necessity to apply a machine-involving treatment of the dental caries. An important factor for taking the decision about treatment is the clinical picture of lesions. Early carious lesion may occur in the form of loss of translucency of enamel, opacity or discoloration visible after drying or on a wet tooth [7]. We should remember, however, that not every opacity and / or discoloration is associated with the presence of dental caries $[6,10]$. Evaluation of color, the depth of the carious lesion is usually based on a subjective judgment of the doctor, i.e., the visual examination [8]. Most difficult is the evaluation of fossa, grooves and pits on the chewing surfaces of posterior teeth where decay most often develops in areas not accessible to the eyes of the doctor (on the lateral surfaces of the walls, rarely at the bottom of grooves) $[6,10]$. The difficulty is even greater when we are dealing with a high 
health-awareness patient (with good oral hygiene, applying fluoride toothpaste and other forms of prevention against caries). This is due to the fact that the carious cavities have complex structural organization consisting of areas of higher and lower mineralization, formed by consecutive cyclic periods following de- and remineralization [5,9].

The study of the enamel in the scanning electron microscope (SEM) allows the analysis of the structure of the enamel at the ultrastructural level. The healthy enamel is an ordered structure of tightly packed hydroxyapatite crystals separated by small intercrystalline areas filled with water and organic material $[12,15]$. Whereas, the image of carious spots in high magnification reveals the increase in the porosity of demineralized enamel with partial irregular dissolution of prisms and enlargement of intercrystalline areas $[6,12,15]$. According to data from the literature, the destruction of enamel prisms runs in three ways: the most common type 1 - with damage to the interior of the prism, type 2 - with the expansion of prismatic shells and type 3 occurs least often and on a small area - with total loss of the structure of the enamel $[12,15]$. It is also known that the abovementioned types of prisms destruction can occur simultaneously in the same lesion $[5,12,15]$. With the change of structural composition of enamel in the early carious lesion the chemical composition of the enamel is also changing consisting in the loss of minerals, mainly calcium and phosphorus [15].

Knowledge of the morphology of hard dental tissues lesions has led to the development of quantitative methods for diagnosis and monitoring of dental caries, which enabled the implementation of appropriate treatments aimed at repairing than replacing damaged tissue.

\section{AIM}

The aim of the study was to compare selected diagnostic methods: visual, impedance spectroscopy and laser fluorescence in detecting caries in grooves on the chewing surfaces of molars and premolars.

\section{MATERIAL AND METHODS}

In vivo studies were performed in patients aged 18-27 years to 56 teeth with no fillings, 20 molars and 36 premolars in which the presence of caries in anatomical pits was macroscopically revealed, and in visual assessment using a six-grade index of International Caries Detection and Assessment System ICDAS, the values of 1 or 2 were assigned. The value 1 is a matte spot, white or brown, visible after drying of the surface, the value 2 is a matte spot, white or brown, visible on the wet surface. Then dentists using CarieScan PRO device that uses the phenomenon of impedance spectroscopy evaluated the chewing surfaces of teeth and the tissue fluorescence was measured using a laser device Diagnodent Pen ${ }^{\circledR}(\mathrm{KaVo})$. The measurements were performed according to the reproducibility procedure. The results indicated by the devices were entered in the prepared examination chart, and then they were referred to the appropriate categories specified by the equipment manufacturers. The obtained data were statistically analyzed.

\section{RESULTS}

During the visual-tactile test, all the examined teeth $(100 \%)$ showed the presence of carious spots (codes 1 and 2 by ICDAS) requiring non-invasive treatment. Accordnig to the criteria of Lussi [11], 26.8\% of examined teeth received the values above 20 by Diagnodent Pen, being an indication for prophylactic measures or micro-invasive treatment depending on the risk of dental caries. The obtained results of evaluation of the occlusal surface of teeth with CarieScan PRO have shown that according to the scale of the manufacturer a low risk of dental caries was found in $20.83 \%$ of the cases, moderate risk of dental caries presence existed in $41.67 \%$ of teeth and a high risk - in $39.5 \%$.

Statistical analysis of test results using the R-Spearman correlation test showed high compliance of measurement results obtained with the Diagnodent Pen device with the visual-clinical test using the ICDAS index. Regardless of the type of encoding used with the results obtained by Diagnodent Pen (direct readings from the unit or the division according to the Lussi criteria), a statistically significant R-Spearman positive correlation with the ICDAS results was showed. There was no statistically significant relationship between the indications obtained by CarieScan PRO and ICDAS results. However, statistically significant or close to statistically significant positive correlations between the measurements using both of the devices CarieScan PRO and Diagnodent Pen were obtained (Table 1).

Table 1. The results of the R-Spearman correlation between the studied variables

\begin{tabular}{|l|c|c|}
\hline \multicolumn{1}{|c|}{ Pair of variables } & R-Spearman & $\mathrm{p}$ \\
\hline ICDAS vs Diagnodent Pen & 0.558760 & 0.000008 \\
\hline ICDAS vs Diagnodent Pen Lussi scale & 0.264683 & 0.048684 \\
\hline ICDAS vs CarieScan PRO & 0.119285 & 0.381221 \\
\hline ICDAS vs CarieScan PRO manufacturer's scale & 0.058079 & 0.670704 \\
\hline CareScan PRO vs Diagnodent Pen & 0.257228 & 0.055641 \\
\hline CarieScan PRO vs Diagnodent Pen Lussi scale & 0.232101 & 0.085196 \\
\hline
\end{tabular}

By assigning the obtained results only to two types needed to take a decision: to treat / not to treat, it was found that a higher proportion of teeth in which there was a high likelihood of dental caries and therapeutic intervention should be taken, was indicated by the CarieScan PRO device (39.3\%) in comparison with Diagnodent Pen (26.8\%). In addition, compliance of measurement results from both of the devices was computed, and it was found that $62.5 \%$ of results of both devices were consistent as to taking invasive treatment (Table 2).

Table 2. Compliance of measurement results of both devices

\begin{tabular}{|l|c|c|c|c|c|c|}
\hline \multirow{2}{*}{ Decision } & \multicolumn{2}{|c|}{ Diagnodent Pen } & \multicolumn{2}{c|}{ CarieScan PRO } & \multicolumn{2}{c|}{ Compliance } \\
\cline { 2 - 6 } & $\mathrm{n}$ & $\%$ & $\mathrm{n}$ & $\%$ & $\mathrm{n}$ & $\%$ \\
\hline To treat & 15 & 26.8 & 22 & 39.3 & \multirow{2}{*}{35} & \multirow{2}{*}{62.5} \\
\hline Not to treat & 41 & 73.2 & 34 & 60.7 & & \\
\hline
\end{tabular}

\section{DISCUSSION}

For years, an objective diagnostic tool has been searched for that would allow early detection of carious lesions and assessment of carious lesions progression over time, which 
in turn would minimize the need for invasive treatment. A particular interest has been enjoyed currently by noninvasive diagnostic methods based on physical phenomena, using knowledge of the changes taking place at the ultrastructural level and in chemical composition of enamel in the course of carious process $[2,3,14]$.

In spite of this, early diagnosis of initial caries and differentiating it with a more advanced form, where medical intervention is necessary due to the removal of caries tissue, is still a challenge for dentistry. Research on new devices that may help the dentist decide about invasive treatment or abandoning it has been still current. Striving to establish a universal system capable of helping in the dental caries diagnosis based on a clinical and visual examination is also topical. International Caries Detection and Assessment System - ICDAS is such a system. Many authors emphasize the appropriateness of this method in the diagnosis of dental caries: the stage and extent of the lesions, as well as high repeatability of the results obtained by ICDAS $[1,4,16]$. Ari T and Ari N., [1] note the high importance of LED lighting and magnification in improving the accuracy of diagnosis when assessing the tooth surface using the ICDAS index. In comparative studies of three methods ICDAS, Diagnodent Pen and CarieScan PRO, Teo TK et al., [16] have found that the greatest repeatability and reliability, both in vivo and in vitro tests was characteristic for the ICDAS system in examining occlusal surfaces of decidous molars. Many authors showed the impact on the differences in the results of studies of the so-called cut-off point in a clinical and visual method using ICDAS. According to them, in a study conducted in vitro on permanent extracted teeth, the increase in cut-off point from 2 to 3 reduces the sensitivity of the method, while at the same time increases its specificity $[4,16]$.

In our research, the ICDAS system was applied to select the teeth for further measurements; teeth with codes 1 and 2 were taken into account, so only those that did not require invasive treatment (preparation of hard tissue). The studies were conducted in vivo, and therefore, it was not possible to have histological verification of the extent of lesions observed on the surface of dental tissues. The results of our study indicate a high concordance of measurements performed with the Diagnodent Pen device with the results of visual examination and a lower compliance of visual examination with the results obtained using the CarieScan PRO. Other authors highlight the accuracy and sensitivity in laser fluorescence used in Diagnodent Pen with values similar to those obtained in the clinical and visual examination, and emphasize the low sensitivity [10] for permanent molar teeth tested in vitro or with high sensitivity - a low specificity of the results obtained for deciduous molars in vivo. The results of in vitro analysis for deciduous teeth were different and with high specificity, low sensitivity of this method was observed. Research of Teo T.K. et al., [16] show a relatively high reproducibility of the results of in vivo and in vitro for the methods used: ICDAS and Diagnodent Pen, while the low reproducibility for the CarieScan PRO device.

\section{CONCLUSIONS}

There is no single, effective and reliable diagnostic method to detect initial caries lesions. A combination of visual and tactile method with tests using advanced technology provides greater opportunity to confirm the diagnosis of carious lesions requiring medical intervention.

\section{REFERENCES}

1. Ari T., Ari N.: The performance of ICDAS-II using low-powered magnification with light-emitting diode headlight and alternating current impedance spectroscopy device for detection of occlusal caries on primary molars. ISRN Dentistry, ID 276070, 2013.

2. Chałas R. et al.: AC-impedance spectroscopy and caries detection. Curr. Iss. Pharm. Med. Sci. 26(3): 344-46, 2013.

3. Chałas R. et al.: Usefulness of AC-impedance spectroscopy technique in occlusal caries determination - own investigations. Curr. Iss. Pharm. Med. Sci. 26(4): 440-42, 2013.

4. Cohen J.E.: The association between CarieScan Pro readings and histologic depth of caries in non cavitated occlusal lesion in vitro. Master's thesis, University of Iowa, 2013.

5. Deyhle H. et al.: Nanostructure of carious tooth enamel lesion. Acta Biomater. 10(1): 355-64, 2014.

6. Ekstrand K.R. et al.: Detection, diagnosing, monitoring and logical treatment of occlusal caries in relation to lesion activity and severity: an in vivo examination with histological validation. Caries Res. 32(4): 247-54, 1998.

7. Ekstrand K.R. et al.: Relationship external and histologic features of progressive stages of caries in the occlusal fossa. Caries Res. 29(4): 243-50, 1995.

8. Gordan V.V. et al.: Restorative treatment thresholds for occlusal primary caries among dentists in the dental practice-based research network. J. Am. Dent. Assoc. 141(2): 171-84, 1993.

9. Hjortsjö C. et al.: A replica technique for studying the effect of fluoride solutions on enamel erosion. Swed. Dent. J. 36(4): 169-78, 2012.

10. Kühnisch J. et al.: In vivo detection of non-cavitated caries lesions on occlusal surfaces by visual inspection and quantitative light-induced fluorescence. Acta Odontol. Scand. 65(3): 183-8, 2007.

11. Lussi A., Schaffner M.: Advances in Restorative Dentistry. Quintessenz Verlogs-GmbH. 2012.

12. Metthews-Brzozowska T., Surdacka A.: Ultrastrukturalny obraz szkliwa w próchnicy początkowej. Czas. Stomat. 43: 447-52, 1990.

13. Mortensen D. et al.: Detection of non-cavitated occlusal caries with impedance spectroscopy and laser fluorescence: an in vitro study. Open Dent. J., 8(4): 28-32, 2014.

14. Neuhaus K.W. et al.: Performance of laser fluorescence devices, visual and radiographic examination for the detection of occlusal caries in primary molars. Clin. Oral Investig. 2011; 15(5): 635-41.

15. Piesiak-Pańczyszyn D., Czajczyńska-Waszkiewicz A., Kaczmarek U.: Analiza porównawcza ultrastrukturalnego obrazu i składu chemicznego wczesnej zmiany próchnicowej i zdrowych tkanek twardych zębów. Dent. Med. Prob. 42(3): 443-48, 2005.

16. Teo T.K., Ashley P.F., Louca C.: An in vivo and in vitro investigation of the use of ICDAS, DIAGNOdent pen and CarieScan PRO for the detection and assessment of occlusal caries in primary molar teeth. Clin. Oral Investig., 18(3): 737-44, 2014. 